\title{
The Fibonacci Life Chart Method as a Predictor of Spiritual Experience
}

\author{
Robert G. Sacco ${ }^{1}$ \\ ${ }^{1}$ Toronto, Canada \\ Correspondence: Robert G. Sacco, Toronto, Canada. E-mail: robgsacco@gmail.com
}

Received: March 15, 2017

Accepted: April 5, 2017

Online Published: April 12, 2017

doi:10.5539/jedp.v7n2p1

URL: http://doi.org/10.5539/jedp.v7n2p1

\begin{abstract}
The Fibonacci Life Chart Method (FLCM) provides a framework linking development and spirituality. This study addressed the need for empirical research to test the hypotheses proposed by Sacco (Sacco, 2016). To address this problem, this study used case reports $(N=196)$ from the Alister Hardy Religious Experience Research Centre. The dynamical aspects of ages 11, 18, and 30 were examined as predictors of increased spiritual experience in adolescents and young adults. Results showed only ages 17 and 18 predicted a higher frequency of spiritual experience between ages 11 and 35. Age 18 was associated with a higher effect size $(r$ $=.27$ ). This finding provides some empirical support for the FLCM as a predictor of spiritual experience, but not all hypotheses found support. Limitations to the study's design are discussed along with implications for future research.
\end{abstract}

Keywords: dynamical systems theory, Fibonacci numbers, Fibonacci Life Chart Method, golden ratio, spiritual experience, synchronicity

\section{Introduction}

Spirituality and religion are central to people worldwide. In the United States, polls show $89 \%$ of respondents believe in God and most are religious, spiritual, or both (Fuller, 2001; Pew Research Center, 2014). Spiritual and religious experiences are also common in the general population. Studies show about $35 \%$ of people have had a spiritual or religious experience (Greeley, 1975; Hay, 1990). The widespread occurrence of spiritual experience contrasts with a lack of research into these complex human experiences (Hood \& Zhuo, 2013). The lack of research, particularly among younger groups, is problematic. Researchers have shown that emerging adults experience a high number of spiritual struggles and are at risk for negative psychological outcomes (Bryant \& Astin, 2008; Exline \& Rose, 2013). This raises questions about whether some spiritual experiences and struggles might be part of a normal developmental process among young adults. Understanding predictors, correlates, and mechanisms of spiritual experience may thus help to improve spiritual struggles.

Adolescence and emerging adulthood provide a useful context to examine the dimensions of spiritual experience, for two reasons. First, studies show that adolescence and emerging adulthood are important developmental periods for spiritual experience. For instance, Smith (2006) found the average age of spiritual transformation was 30 years and signified that early adulthood is the most common period. Indeed, $60 \%$ of subjects reported they were under 29 when their spiritual transformation occurred (Smith, 2006). Second, spiritual experience appears linked to identity growth during late adolescence and emerging adulthood. As Erikson proposed personality develops in eight epigenetic stages over the course of the life span (Erikson, 1982; Sacco, 2013). The main developmental task of late adolescence and emerging adulthood is to establish a personal identity. This suggests that developmental changes in identity might explain changes in spirituality. Thus, the developmental origins of spiritual experience deserve further attention.

To better understand the relationship between age and spiritual experience, Sacco (2016) described a new method, termed the Fibonacci Life Chart Method (FLCM). Derived from dynamical systems theory, the FLCM provides a mathematical framework for human development (Sacco, 2013). The FLCM outlines eight stages in human development based on the Fibonacci sequence. Waskom (1972) first theorized that human development stages might follow the Fibonacci sequence. To describe human development with the Fibonacci sequence, Waskom asserted the numbers that mark human developmental stages are the same numbers expressed in the 
Fibonacci sequence: 1, 5, 8, 13, 21, 34, and 55 (Rose, 1991). In contrast, Sacco (2013) suggested it was not clear why Fibonacci numbers must have numeric values in years. Sacco claimed a more useful taxonomy of the Fibonacci numbers is the 24-hour day/night cycle. For example, human embryonic cells have a doubling time of 24 hours (Lagarkova, Eremeev, Svetlakov, Rubtsov, \& Kiselev, 2010). Yet whether the FLCM based on a 24-hour cycle has a direct effect on human outcomes has not been shown.

The importance of the Fibonacci numbers comes from several sources. Many physical and biological systems have structures that approximate Phi, an irrational number (about 1.618034), also known as the "golden ratio". The relation between Fibonacci numbers and the golden ratio is that the ratios of the successive numbers in the Fibonacci sequence converge on the golden ratio (Grattan-Guinness, 2002). Harmonic characteristics related to the golden ratio appear in the arrangement of leaves on a plant stem (Okabe, 2011), spiral structures of galaxies (Grattan-Guinness, 2002), pulse frequency of a star (Lindner et al., 2015), quantum phase transition (Coldea et al., 2010), nucleotide frequencies (Yamagishi \& Shimabukuro, 2008), and cell (Staff et al., 2012) and shell (Gosling, 2008) growth. In human science, the golden ratio has been observed in body proportions (Ferring \& Pancherz, 2008), bronchial airway segment bifurcations (Goldenberger, West, Dresselhaus, \& Bhargava, 1985), gait phases of walking (Iosa et al., 2013), hair whorls (Paul, 2016), and aesthetic preference (Ricketts, 1982; Russell, 2000).

\subsection{The FLCM and Spiritual Experience}

Of possible further significance of the golden ratio to human perception might be spiritual and religious experience. As William James (1902/1985) noted over 100 years ago, spiritual experiences are diverse. Most modern researchers would agree that religion and spirituality overlap, but are distinct constructs (e.g., Piedmont, 2005; Zinnbauer \& Pargament, 2005). Religiosity involves participation in collective beliefs, activity, and ceremonies of traditional organized religions. A religious experience therefore relates to a particular religious doctrine (e.g., listening to a sermon, reading the Bible, or alone in church). Spirituality involves a personal subjective experience of the sacred. A spiritual experience therefore transcends the ordinary aspects of daily life. More common spiritual experiences encompass awe and joy that lifts one out of the mundane (Underwood \& Teresi, 2002). Spiritual experiences, however, also relate to more paranormal phenomena (e.g., Hood \& Zhuo, 2013; Kelly \& Tucker, 2015). A paranormal experience deviates from "every day" causal principles.

Hardy's (1979) analysis of 3,000 case reports classified spiritual or religious experience into eight major types: synchronicity and patterning of events, presence of God, answered prayer, presence not called God, sacred presence in nature, experiencing that "all things are one", presence of the dead, and presence of evil. Furthermore, "synchronicity and patterning of events" is the most commonly reported category of spiritual experience (Hay, 1990). Of the people who reported experience of synchronicity, only $32 \%$ regarded this as religious (Hay, 1990). In addition to Hardy's categories, two more types of classification based on the context of the experience are: (a) crisis experiences, and (b) non-crisis experiences. Distinct differences exist between crisis experiences and non-crisis experiences. For example, a crisis can often stimulate creative thinking or encourage new goals. Hence, crisis experiences may emerge more "spontaneously" resulting not from specific practices, but as resolution and solutions to problems (Batson, Schoenrade, \& Ventis, 1993). Also, a crisis often involves emotions of fear, grief, or other powerful emotions.

The claim the golden ratio might relate to spiritual experience is made more plausible by three sets of empirical findings. First, spiritual experiences tend to occur in contexts of stress and crisis (James, 1902/1985; Smith, 2006). From a dynamical systems perspective, stress or crisis can act as a perturbation causing a change in system parameters. Complex systems resist changes to their attractor states. However, when the perturbation is strong enough, a system can move from a more stable dynamical attractor pattern to a less stable attractor pattern (Thelen \& Smith, 1994). Such a transition in a complex system is referred to as a "phase transition" a brief chaotic period. Phase transitions are critical points in dynamic systems. They also relate to the Fibonacci sequence (Linage, Montoyaa, Sarmientob, Showalter, \& Parmananda, 2006). Specifically, the Fibonacci sequence appears within the Feigenbaum scaling of the period doubling cascade to chaos (Linage et al., 2006). Thus, the Fibonacci sequence is at the root of dynamical phase transition.

Second, at the core of spiritual experience is a sense of unity (Hardy, 1979; James, 1902/1985). Why might spiritual experience relate to a sense of unity? It may be helpful to consider the dynamical aspects of phase transitions. Empirically, the critical dynamics of phase transitions are shown to have nonlocal and fractal connectivity. Nonlocality refers to correlations between spatially separated events (Stapp, 2009). A fractal is a symmetry having a pattern that repeats at different scales (Bak, 1996). Significantly, fractal geometry includes 
the Fibonacci sequence as a unifying theme (Devaney, 1999). Perhaps, too, there is a unity found in nonlocality, fractals, the Fibonacci sequence, and spiritual experience (Sacco, 2016). If spiritual experiences involve emergent dynamics within a stressed state (e.g., Smith, 2006), then it is logical to assume that spiritual experience relates to nonlocality and fractals generally, and particularly experiences of ultimate meaning, unity, and interconnectedness (Hogenson, 2005, 2014; Sacco, 2016).

Third, people often describe the feeling of spiritual experience as beauty, harmony, and love. Likewise, aesthetic consideration has surrounded the golden ratio ever since humans first reflected on the geometric forms of the world. The golden ratio appears in the sacred art of Egypt, India, China, Islam and other traditional civilizations (Livio, 2008). The golden ratio was called the "divine proportion" during the Renaissance, from the title of a book published by the mathematician Luca Pacioli in 1509 (Huntley, 1970), and illustrated by Leonardo da Vinci. The golden ratio, or divine proportion, has for centuries represented perfect harmony, or the most attractive proportion in almost all things. Thus, the same sense of harmony perceived in the dimension of space may also be perceived in time (Sacco, 2016). As shown above, there are reasonable theoretical grounds that FLCM could provide a model for researchers to explore spiritual experience.

\subsection{The Present Study}

The goal of this study was to examine how dynamical aspects of FLCM ages 11, 18, and 30 may predict increased spiritual experiences. This study focused on adolescence and emerging adulthood as important developmental periods for spiritual experience. The study data is from the Alister Hardy Religious Experience Research Centre (RERC), an extensive database of over 6,000 accounts of spiritual experience collected since 1969. To examine the adolescence and emerging adulthood period only data between ages 11 and 35 was used. Based on the FLCM it was hypothesized ages 11, 18, and 30 may predict a higher frequency of spiritual experience.

\section{Method}

\subsection{Study Samples}

The Study Sample comprised accounts of religious or spiritual experience received by the Alister Hardy Religious Experience Research Centre (RERC) in response to mass-media appeals. Respondents were from different regions around the world and religious backgrounds. The entire database comprised 6,482 respondents. With access to such a vast and diverse pool of subjects, it was possible to select test cases strategically. The inclusion/exclusion criteria were:

(1) Single experience: Respondents with multiple experiences were excluded as single experiences would mean the most memorable experience.

(2) Adequate age specification: Some respondents provided an age range (e.g., "21-23") or life stage (e.g., "teens, young adult"), and not a single discrete age. This data was excluded as it did not enable measures of central tendency.

(3) Adolescence and emerging adulthood: This paper defined adolescence and emerging adulthood as persons between ages 11 and 35. Therefore, age of writing and age of experience was restricted between these ages.

The database search spanned all years since 1969 up to the present study. The electronic search yielded 196 case reports that met inclusion criteria and thus warranted further review. Table 1 shows application of the exclusion criteria. Collection of demographic data also allowed an analysis of the representativeness of the Sample.

Table 1. Exclusion criteria for the study of spiritual experience

\begin{tabular}{|c|c|c|c|c|}
\hline & & Available for analysis & Excluded $n$ & Included $n$ \\
\hline & & $N=6,482$ & & \\
\hline \multicolumn{5}{|l|}{ Age of experience } \\
\hline & Not specified & & 3,024 & \\
\hline & Multiple ages/not adequately specified & & 1,888 & \\
\hline & Age of experience $<11$ & & 78 & \\
\hline & Age of experience $>35$ & & 551 & \\
\hline
\end{tabular}


Age of writing

$\begin{array}{lc}\text { Not specified } & 103 \\ \text { Not adequately specified } & 50 \\ \text { Age of writing }<11 & 1 \\ \text { Age of writing }>35 & 59\end{array}$

103

50

1

591

196

\subsection{Materials}

The Fibonacci Life Chart Method (Sacco, 2013, 2016) was used to generate chronological ages. Table 2 shows calculation of FLCM chronological ages. As shown in Table 2, the FLCM generates a pattern characterized by eight age groups: early infancy (0-2), toddler (2-4), early childhood (4-7), middle childhood (7-11), adolescence (11-18), young adulthood (18-29), middle adulthood (29-48), and older adulthood (48-78+) (Sacco, 2013). The model hypothesizes that these ages are biological phase transitions and marked by potential changes in identity.

Table 2. The Fibonacci Life Chart Method

\begin{tabular}{|c|c|c|}
\hline Fn & Date & Chronological Age \\
\hline 0 & January 1, 2000 & 0.00 \\
\hline 1 & January 2, 2000 & 0.00 \\
\hline 1 & January 3, 2000 & 0.01 \\
\hline 2 & January 5, 2000 & 0.01 \\
\hline 3 & January 8,2000 & 0.02 \\
\hline 5 & January 13,2000 & 0.03 \\
\hline 8 & January 21, 2000 & 0.05 \\
\hline 13 & February 3, 2000 & 0.09 \\
\hline 21 & February 24, 2000 & 0.15 \\
\hline 34 & March 29, 2000 & 0.24 \\
\hline 55 & May 23, 2000 & 0.39 \\
\hline 89 & August 20, 2000 & 0.64 \\
\hline 144 & January 11, 2001 & 1.03 \\
\hline 233 & September 1, 2001 & 1.67 \\
\hline 377 & September 13, 2002 & 2.70 \\
\hline 610 & May 15, 2004 & 4.37 \\
\hline 987 & January 27, 2007 & 7.08 \\
\hline 1597 & June 12, 2011 & 11.45 \\
\hline 2584 & July 9, 2018 & 18.53 \\
\hline 4181 & December 19, 2029 & 29.99 \\
\hline 6765 & June 27, 2048 & 48.52 \\
\hline 10946 & June 16, 2078 & 78.51 \\
\hline
\end{tabular}

Note. Fibonacci numbers represent 24-hour days.

\subsection{Search Procedure}

The Alister Hardy electronic database was comprehensively searched. The data reported in this paper was collected from July 2016 to September 2016. No date restrictions or keywords were imposed on the searches. 
Case reports were generated only with the main search box button, which retrieved the entire database of 6,482 case reports. An automated web scraping system was used to extract data from the webpages (Landers, Brusso, Cavanaugh, \& Collmus, 2016). The extracted data was exported to Microsoft Excel (version 2013; Microsoft, Redmond, WA). With the scraped dataset, sorting of age variables was performed with the filter function in Microsoft Excel.

Case reports were filtered based on: (a) single experiences, (b) adequate age specification, and (d) age of experience and age of writing $\geq 11$ and $\leq 35$. Ages could be rapidly sorted as single integers with the filter function in Microsoft Excel. This sorted all missing ages, or those not adequately specified, into a separate column. For example, to the age of experience question, some respondents provided no answer. Others answered with multiple ages (e.g., "12, 22, 31"), an age range (e.g., "21-23”), or life stage (e.g., "teens, young adult"). Others were unsure (e.g., "about 20", "11 or 12"). All irrelevant case reports were excluded from further analysis. This created a column of single age integers for analysis and comparison. The exclusion criteria resulted in 196 relevant case reports (Table 1). All ages were then sorted from low numbers to high numbers. Ages were then compared for age matches. A match corresponded to the age of experience equaling age 11, 18, or 30 . The Microsoft Excel auto-sum function totaled up age matches.

\subsection{Statistical Analysis}

Statistical analysis of the data was performed using Microsoft Excel (version 2013; Microsoft, Redmond, WA) and GraphPad Prism version 7.00 for Windows (GraphPad Software, San Diego, California, USA). Microsoft Excel generated descriptive statistics, while GraphPad Prism produced inferential statistics. The chi-square test for goodness of fit was used to compare observed and expected frequencies. The chi-square test can satisfactorily compare the observed distribution of data to an expected distribution. Statistical significance was set at $p<.05$.

\section{Results}

Of the 196 case reports, demographic results show that most respondents were female (62\%), Christian (68\%), and were from the United Kingdom (65\%) (Table 3). The age of writing range was 14 to $35\left(M_{\text {age of writing }}=27.13\right)$. The age of experience range was 11 to 35 ( $\left.M_{\text {age of experience }}=21.46\right)$. Mean temporal distance between age of writing and age of experience was 5.67 years. The probability distribution for age of experience is shown in Figure 1. As shown in Figure 1, ages 17 and 18 show a significant peak. Age 18 has the highest reporting level compared to the other ages.

Table 3. Demographic characteristics of the study sample

\begin{tabular}{|c|c|c|c|}
\hline Variable & & \# & $\%$ \\
\hline \multicolumn{4}{|l|}{ Gender } \\
\hline & Male & 70 & $35.7 \%$ \\
\hline & Female & 121 & $61.7 \%$ \\
\hline & Not specified & 5 & $2.6 \%$ \\
\hline \multicolumn{4}{|c|}{ Religious background } \\
\hline & Agnostic & 1 & $0.5 \%$ \\
\hline & Atheist & 3 & $1.5 \%$ \\
\hline & Buddhist & 2 & $1.0 \%$ \\
\hline & Christian & 134 & $68.4 \%$ \\
\hline & Jewish & 6 & $3.1 \%$ \\
\hline & No Allegiance & 10 & $5.1 \%$ \\
\hline & Not specified & 40 & $20.4 \%$ \\
\hline \multicolumn{4}{|l|}{ Country } \\
\hline & Other & 17 & $8.7 \%$ \\
\hline & United Kingdom & 127 & $64.8 \%$ \\
\hline & USA & 29 & $14.8 \%$ \\
\hline
\end{tabular}


Age of writing

$\begin{array}{lll}<11 & --^{\mathrm{a}} & -- \\ 11-19 & 27 & 14.2 \% \\ 20-29 & 86 & 45.3 \% \\ 30-35 & 83 & 43.7 \% \\ >35 & --^{\mathrm{b}} & -- \\ \text { Not specified } & 0 & 0.0 \% \\ \text { Mean } & 27.13 & \end{array}$

Note. Other countries include: Australia, Austria, Canada, Japan, South Africa, Spain, Sweden, and Turkey.

${ }^{\text {a }}$ No case reports for age of writing $<$ age 11 were included.

${ }^{\mathrm{b}}$ No case reports for age of writing $>$ age 35 were included.

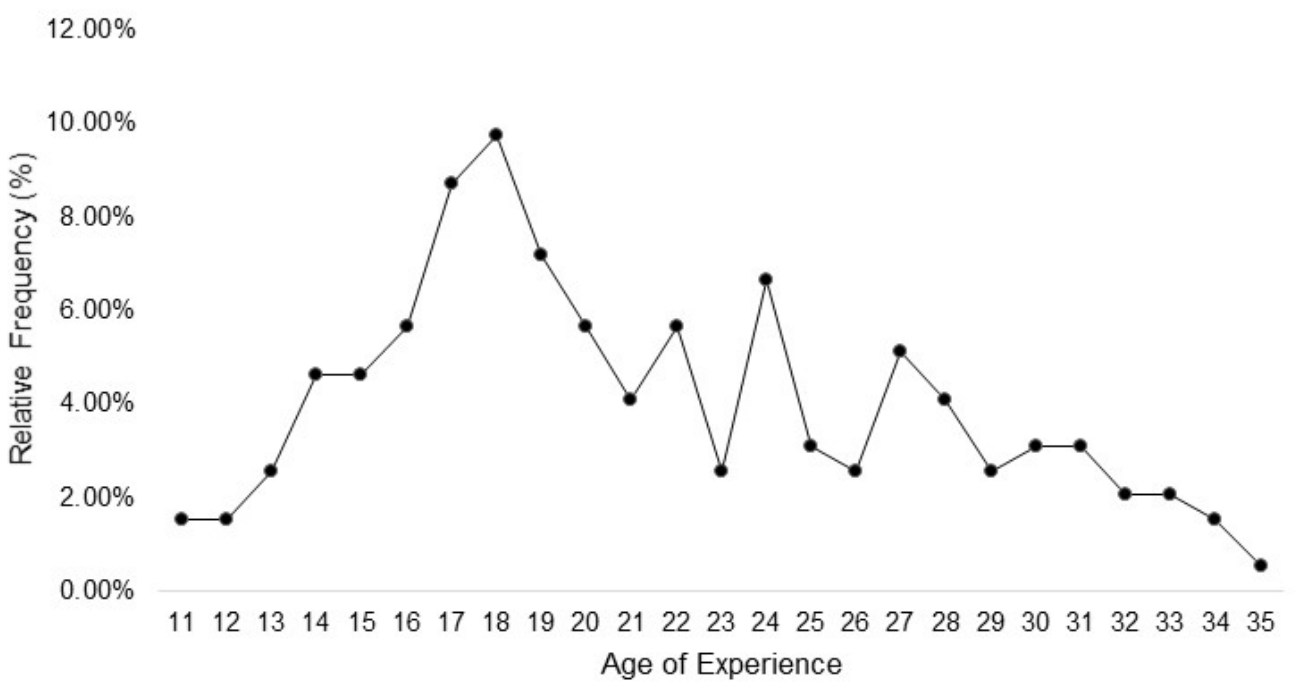

Figure 1. Distribution of spiritual experience (relative probability) as a function of reported age of experience summarized for ages 11 to 35

It was hypothesized that ages 11,18 , and 30 would predict increased spiritual experiences. To examine the association between ages $11,18,30$ and spiritual experiences, case reports $\left(N=196 ; M_{\text {age of writing }}=27.13\right)$ were checked for age matches. Of the 196 case reports, there were: (a) 3 matches at age 11; (b) 19 matches at age 18; and (b) 6 matches at age 30. For purposes of answering the research question, the expected and observed frequencies of matches were compared (see Table 4). The expected proportion is the probability of a match occurring randomly; obtained by dividing the number of possible matches by the age range. For example, the probability for age 11 was calculated as $[1=(11)]$ divided by the age range $[24=(35-11)]$. The expected proportion is, therefore, .042 match and .958 mismatch. Table 4 shows the chi-square contingency table analysis. 
Table 4. Comparison of observed and expected distributions of spiritual experience matches

\begin{tabular}{|c|c|c|c|}
\hline & Observed $n$ & Expected $n$ & Expected \% \\
\hline & \multicolumn{3}{|c|}{ Age 11} \\
\hline Match & 3 & 8.23 & .042 \\
\hline \multirow[t]{2}{*}{ Mismatch } & 193 & 187.77 & .958 \\
\hline & \multicolumn{3}{|c|}{ Age 18} \\
\hline Match & 19 & 8.23 & .042 \\
\hline \multirow[t]{2}{*}{ Mismatch } & 177 & 187.77 & .958 \\
\hline & \multicolumn{3}{|c|}{ Age 30} \\
\hline Match & 6 & 8.23 & .042 \\
\hline Mismatch & 190 & 187.77 & .958 \\
\hline
\end{tabular}

The results of the chi-square test for goodness of fit showed the observed frequency of matches for age 18 significantly departed from the expected distribution in a positive direction, $\quad(N=196)=14.70, p<.001$. The overall weighted mean effect size was .27 , a medium effect size. Thus, the hypothesis that age 18 predicts an increase in the frequency of spiritual experience appears to receive strong support $(p<.05)$. The results of the chi-square test for goodness of fit showed the observed frequency of matches for FLCM ages 11 and 30 did not significantly depart from the expected distribution, $\quad(N=196)=3.47, p=.063$ and $\quad(N=196)=0.63, p$ $=.427$. The only other age with a significant test statistic was age $17, \quad(N=196)=9.75, p<.002$. Age 17 corresponded to a smaller resulting effect size (.22). Thus, overall, the hypothesis that FLCM ages predict an increase in the frequency of spiritual experience appears to receive support only for age $18(p<.05)$.

\section{Discussion}

In a previous paper (Sacco, 2016), it was shown how FLCM could be used as a theoretical framework for systematic empirical research into spiritual experience. In this article, the goal was to test whether the dynamical aspects of ages 11, 18, and 30 predict a higher frequency of spiritual experience. Data from this study indicate only ages 17 and 18 predict an increase in spiritual experiences among adolescents and young adults. Age 18 was associated with a higher overall effect size $(r=.27)$. This finding supports the hypothesis that age 18 is a dynamical system attractor for spiritual experience among adolescents and young adults.

\subsection{Phase Transition and Spiritual Experience}

The findings presented here have implications for several broader issues. The findings suggest that personality changes between ages 17-18 may predispose some people to higher levels of spiritual experience. Adolescence and early adulthood are a unique period because of the biological maturation of different brain regions and circuits (e.g., Dumontheil, 2014). Therefore, one would expect some stability in the onset and offset of sensitive periods. This feature of sensitive periods is an essential premise of Erikson's life stage theory (Erikson, 1982). FLCM builds on Erikson's life stage theory by outlining eight stages in the human lifespan based on the Fibonacci sequence (Sacco, 2013). A basic premise of FLCM is these eight stages occur as biologically determined phase transitions from one attractor state to another. The transition marks the end of one period of stability and emergence of another (Sacco, 2013). This hypothesis is in accord with several studies that show FLCM ages (i.e., 1, 2, 4, 7, 11, 18, 30, 48, and 78) relate to significant biological and psychological changes.

For instance: (a) all major theories describe intellectual development with transitions at 1-2, 6-7, and 11-12 years associated with increasingly abstract representations (e.g., Piaget, 1970; Case, 1985), and cortical gray matter volume, reflecting neuronal density and the number of connections between neurons, peaks around age 11 (e.g., Giedd, 2004); (b) puberty begins around ages 10-11 in girls and ages 11-12 in boys (Kail \& Cavanaugh, 2010) and male testosterone peaks at age 18-19 (e.g., Kelsey, Li, Mitchell, Whelan, Anderson, \& Wallace, 2014); (c) the final stage of third molar development occurs at age 18 (Roberts, Lucas, Andiappan, \& McDonald, 2017); (d) personality stability becomes fixed at age 30 (e.g., Terracciano, Costa, \& McCrae, 2006); (e) happiness levels are lowest at age 48.5 around the world (Blanchflower \& Oswald, 2008); (f) the average age at menopause marking the end of the fertile lifespan has remained constant at 50 years old (e.g., Tehrani, Solaymani-Dodaran, Tohidi, 
Gohari, \& Azizi, 2013); and (g) the average age of onset for dementia in males is 78.8 (Brinks, Landwehr, \& Waldeyer, 2013).

Collectively, these findings imply a unique role of FLCM ages in predicting biological and psychological phase transition. These phase transitions can result from self-organization processes at multiple levels (e.g., molecules, genes, cell, organ, organ system, organism, behavior, and environment) that can influence each other (Thelen \& Smith, 1994). Similarly, the association of age 18 with increased spiritual experience imply a critical period for the development of identity due to major physical, cognitive, and social changes. Theoretically, FLCM ages may be conceived as an internal timing mechanism that start a transformation of an attractor's objective phase space. Dynamical systems attractors are characterized by a complex and fractally arranged folding of space called chaotic or strange attractors (Thelen \& Smith, 1994). With strange attractors, the attractor ends up filling a definite fraction of space with points (i.e., it is fractal). Thus, age 18 might be a strange attractor for spiritual experience.

\subsection{The Nature of Spiritual and Religious Experience}

A broader issue concerns the nature of spiritual experience. The classic text in the psychology of religion is The Varieties of Religious Experience (James, 1902/1985), and is subtitled "a study in human nature". This implies that psychologists ought to be interested in spiritual and religious experiences insofar as they are part of human nature. Surprisingly, theories and models of spiritual experience are largely devoid of reference to the natural sciences or human development. Dynamical systems theory is an approach that has transformed the natural sciences (Abraham \& Shaw, 1992; Haken, 2002; Thelen \& Smith, 1994). This perspective resonates especially well with enduring issues in spiritual experience research, and thus serves as a valuable integrative framework for research and theory construction. The dynamical perspective provides a set of principles, methods, and tools that impose precision on topics often opaque when viewed through traditional lenses.

Since the work of James (1902/1985) more than 100 years ago, psychologists have recognized the central role of stress and crisis to spiritual experience. In the current study, upon review of case reports at age 18, a large number (over 50\%) of descriptions related to problems or a crisis event. Dynamical systems theory provides a scientific model for how humans self-organize and change over time (Thelen \& Smith, 1994). Modern dynamical systems theory can help in understanding how spiritual experiences evolve during times of stress and crisis. For example, (a) an extreme amplification of chaos may create a crisis, (b) the process of destabilization and restabilization through self-organization, (c) the ability of self-organizing systems to "solve" problems, (d) feeling sudden change, (e) the sense of interconnectedness with the rest of reality, (f) awareness of an emergent pattern of life, $(\mathrm{g})$ and perception of unity.

Clearly, the components of spiritual experience align empirically and conceptually with dynamical systems theory. Therefore, integration with dynamical systems theory can proceed from the premise that the same patterns that underlie dynamical phase transition also underlie spiritual experience (Sacco, 2016). Most importantly, FLCM predicts many spiritual experiences involve the dynamical aspects of fractals and nonlocality (Sacco, 2016). Researchers have begun to explore how synchronicity experiences could relate to quantum nonlocality (e.g., Carminati \& Martin, 2008; Martin, Carminati, \& Carminati, 2010). The possibility of a macroscopic cognitive effect responding to quantum effects is of interest given the new field of "quantum biology". Among the variety of biological phenomena that fall within the emerging field of quantum biology are olfaction (Turin, 2002), photosynthesis (Sarovar, Ishizaki, Fleming, \& Whaley, 2010), DNA mutation (Löwdin, 1966), and the navigation of some bird species via magnetic field sensing and quantum entanglement (Rodgers \& Hore, 2009).

\subsection{Strengths and Limitations}

This project represents one of the first attempts to predict spiritual experience developmentally. It used a comprehensive international database. Data collection included automated and targeted extraction for statistical analyses. Consequently, the overall effect of coding errors is expected to be zero. The study also benefited from a large sample size to ensure enough statistical precision. Although the present study contributes to the literature by testing the predictions of FLCM, this study is preliminary due to several limitations.

The most general limitation is the accuracy of the data. Retrospective memory is a major issue in this study. Since the respondents reflected on their personal experiences, the memories could have been inaccurate. An ongoing debate relates to the reliability of adult memory. Some research points toward the view that memory 
decays with age and so memories can become distorted, but other research suggests memories are remembered well into adulthood (Kvavilashvili, Kornbrot, Mash, Cockburn, \& Milne, 2009).

Also, the present sample, although international, mainly represented people from the United Kingdom or USA (79.6\% of international respondents) who were Christian. Obviously, this demographic constraint limits the generalizability to other samples (e.g., non-Western, non-Christian). Future work should examine the predictive relationships between development and spiritual experience in a diverse set of religious affiliations to determine whether development impacts spiritual experience differently in different faith traditions (or between religious and non-religious people).

A further issue is construct validity. The aggregation of religious and spiritual experiences raises the concern of construct overlap, because these are considered distinct constructs (Piedmont, 2005; Zinnbauer \& Pargament, 2005). This may cause misclassification that affects the representativeness of the system. In this regard, what is important is the upward or downward trends observed with the stability of this form of reporting.

Finally, the present study excluded respondents who had multiple experiences. Conventionally, when researchers ask participants to report on their personal experiences, they often ask to select one particular episode (i.e., the one they remembered best). However, categorizing data based on single experiences may not have distinguished the most important experiences. The estimated $50 \%$ trimming of data potentially affects the external validity of the study. Yet it is not expected to affect the results in a way that would alter the main conclusions of the article.

\subsection{Recommendations for Future Research}

In clinical settings, this work helps to understand the etiology of spiritual experience. It is important to consider the implications of spiritual experience due to the long term impact on well-being (Bryant \& Astin, 2008; Exline $\&$ Rose, 2013). Evidence suggests crisis and disequilibrium are precursors to spiritual struggle, and that spiritual struggle is a precursor to spiritual growth (Desai \& Pargament, 2015; Werdel, Dy-Liacco, Ciarrocchi, Wicks, \& Breslford, 2014). However, if a person is not supported through this process, then the possibility for healthy growth may be hindered. This suggests early intervention is needed to prevent maladaptive behavior patterns which may accompany unresolved spiritual struggles (Dworsky, Pargament, Wong, \& Exline, 2016).

To the extent that FLCM is a valid predictor of spiritual experience requires clarification. The present study provided no direct evidence of an association between ages 11 and 30 and increased spiritual experience as predicted by FLCM. However, this does not mean the ages are without importance. Instead, alternative interpretations of the results should be considered. One explanation is that certain types of spiritual experience may depend on adult-like cognitive skills such as abstract thinking (Fowler, 1995). For instance, synchronicity arises from integrating symbols and experience (Jung, 1952). This depends on abstract thinking only emerging around age 11 (e.g., Dumontheil, 2014). Thus, maturity could influence a capacity for spiritual awareness.

Another possible explanation why ages 11 and 30 did not predict increased spiritual experience includes the identity formation process. Erikson coined the term identity crisis to describe the uncertainty and anxiety adolescents experience as they struggle with alternatives and choices (Erikson, 1982). Erikson contended the difficult aspects of identity crises are often resolved between ages 15-18. If identity crisis and resolution predict spiritual experience, then most spiritual experiences should occur during the identity formation process. This understanding appears to fit the present data: Ages 17 and 18 had the highest reporting level compared to other ages. Presumably, because these ages represent significant developmental changes in identity.

The identity formation process may explain why ages 11 and 30 were not strong predictors of spiritual experience. Children aged 11 have neither thought much about nor resolved identity questions. While adults aged 30 are more likely to have resolved identity issues and achieved a stable identity by making personal commitments to various life domains (e.g., Terracciano, Costa, \& McCrae, 2006). This stability means that after age 30 , while also open and flexible, the system dynamics may crystalize in attractor states (Thelen $\&$ Smith, 1994). To support this understanding, evidence exists that personality and self-concept predict the experience of spiritual struggles (Grubbs, Wilt, Stauner, Exline, \& Pargament, 2016).

To further this program of research, future studies should replicate it with various changes. One change should be to include questionnaires that address the concept of synchronicity. Researchers could administer synchronicity questionnaires to various selected populations. Prime candidates include people interested in parapsychology and spiritual groups. Specifically, it would be worthwhile to conduct this research with a group of clients involved in Jungian-oriented psychotherapy. Many examples of Jung's theories (e.g., archetypes and the collective unconscious) can support synchronicity observations. Researchers should also have subjects keep 
detailed diaries of their synchronicity experiences over extended periods. This will provide an accurate source of memories for testing. These changes will increase internal and external validity.

Finally, the extent these findings generalize to FLCM secondary and tertiary date intervals requires clarification (Sacco, 2016). The dynamics of secondary and tertiary date intervals may depend on the degree of coupled interactions within a synchronized system (Hogenson, 2014). Considering these dynamics can manifest in subtle ways requires careful attention to the complex interactions among the person's development. Researchers might expect the FLCM to be more readily studied during the identity formation process between ages 18 and 29. Since interactions between development and spiritual experience may be most intense during this period.

\section{Conclusion}

This study examined whether the dynamical aspects of ages 11,18 , and 30 predict increased spiritual experience in adolescents and young adults. The results showed age 18 predicted increased spiritual experience. However, ages 11 and 30 did not predict increased spiritual experience. The data from this study suggest age 18 is a dynamical system attractor for spiritual experience, as predicted by the FLCM. The implication is that developmental changes in identity may be predictors of increased spiritual experience. These findings point to the intricate relationship between development and spiritual experience, and suggest the need to understand development as a contributing factor to spiritual experience.

\section{Acknowledgments}

I am grateful to the Alister Hardy Trust and the Alister Hardy Religious Experience Research Centre, University of Wales Trinity Saint David, Lampeter, UK, for permission to access their archive of spiritual accounts and publish this research. Request for copies of the study data set should be addressed to robgsacco@gmail.com.

\section{References}

Abraham, R. H., \& Shaw, C. D. (1992). Dynamics: The geometry of behavior. Redwood City: Addison-Wesley.

Bak, P. (1996). How nature works: The science of self-organized criticality. New York, NY: Springer. https://doi.org/10.1007/978-1-4757-5426-1

Batson, C. D., Schoenrade, P., \& Ventis, W. L. (1993). Religion and the individual: A social psychological perspective. New York, NY: Oxford University Press.

Blanchflower, D. G., \& Oswald, A. J. (2008). Is well-being U-shaped over the life cycle? Social Science \& Medicine, 66, 1733-1749. https://doi.org/10.1016/j.socscimed.2008.01.030

Brinks, R., Landwehr, S., \& Waldeyer, R. (2013). Age of onset in chronic diseases: New method and application to dementia in Germany. Population Health Metrics, 11(1), 6. https://doi.org/10.1186/1478-7954-11-6

Bryant, A. N., \& Astin, H. S. (2008). The correlates of spiritual struggle during the college years. The Journal of Higher Education, 79, 1-27. https://doi.org/10.1353/jhe.2008.0000

Carminati, G. G., \& Martin, F. (2008). Quantum mechanics and the psyche. Physics of Particles and Nuclei, 39(4), 560-577. https://doi.org/10.1134/S1063779608040047

Case, R. (1985). Intellectual development: Birth to adulthood. New York, NY: Academic Press.

Coldea, R., Tennant, D. A., Wheeler, E. M., Wawrzynska, E., Prabhakaran, D., Telling, M., ... Kiefer, K. (2010). Quantum criticality in an Ising chain: Experimental evidence for emergent E8 symmetry. Science, 327(5962), 177-180. https://doi.org/10.1126/science.1180085

Desai, K. M., \& Pargament, K. I. (2015). Predictors of growth and decline following spiritual struggles. The International Journal for the Psychology of Religion, 25(1), 42-56. https://doi.org/10.1080/10508619.2013.847697

Devaney, R. L. (1999). The Mandelbrot set, the Farey tree, and the Fibonacci sequence. The American Mathematical Monthly, 106(4), 289-302. https://doi.org/10.2307/2589552

Dumontheil, I. (2014). Development of abstract thinking during childhood and adolescence: The role of rostrolateral prefrontal cortex. Developmental Cognitive Neuroscience, 10, 57-76. https://doi.org/10.1016/j.den.2014.07.009

Dworsky, C. K. O., Pargament, K. I., Wong, S., \& Exline, J. J. (2016). Suppressing spiritual struggles: The role of experiential avoidance in mental health. Journal of Contextual Behavioral Science, 5(4), 258-265. https://doi.org/10.1016/j.jcbs.2016.10.002 
Erikson, E. H. (1982). The life cycle completed. New York, NY: Norton.

Exline, J. J., \& Rose, E. D. (2013). Religious and spiritual struggles. In R. F. Paloutzian, \& C. Park (Eds.), Handbook of the psychology of religion and spirituality (2nd ed., pp. 380-398). New York, NY: Guilford. https://doi.org/10.1037/14045-025

Ferring, V., \& Pancherz, H. (2008). Divine proportions in the growing face. American Journal of Orthodontics and Dentofacial Orthopedics, 134(4), 472-479. https://doi.org/10.1016/j.ajodo.2007.03.027

Fowler, J. W. (1995). Stages of faith: The psychology of human development and the quest for meaning. New York, NY: Harper One.

Fuller, R. C. (2001). Spiritual, but not religious: Understanding unchurched America. New York, NY: Oxford University Press. https://doi.org/10.1093/0195146808.001.0001

Giedd, J. N. (2004). Structural magnetic resonance imaging of the adolescent brain. Annals of the New York Academy of Sciences, 1021(1), 77-85. https://doi.org/10.1196/annals.1308.009

Goldenberger, A. L., West, B. J., Dresselhaus, T., \& Bhargava, V. (1985). Bronchial asymmetry and Fibonacci scaling. Cellular and Molecular Life Sciences, 41, 1537-1538. http://dx.doi.org/10.1007/BF01964794

Gosling, E. (2008). Bivalve molluscs: Biology, ecology and culture. Oxford, UK: Blackwell Science.

GraphPad Prism [Computer software]. (2016). Retrieved from http://www.graphpad.com

Grattan-Guinness, I. (Ed.). (2002). Companion encyclopedia of the history and philosophy of the mathematical sciences. London, UK: Routledge.

Greeley, A. (1975). The sociology of the paranormal. Beverly Hills, California: Sage Publications.

Grubbs, J. B., Wilt, J., Stauner, N., Exline, J. J., \& Pargament, K. I. (2016). Self, struggle, and soul: Linking personality, self-concept, and religious/spiritual struggle. Personality and Individual Differences, 101, 144-152. https://doi.org/10.1016/j.paid.2016.05.365

Haken, H. (2002). Brain dynamics. Berlin, Heidelberg: Springer.

Hardy, A. (1979). The spiritual nature of man: A study of contemporary religious experiences. New York, NY: Oxford University Press.

Hay, D. (1990). Religious experience today: Studying the facts. London, UK: Mowbray.

Hogenson, G. B. (2005). The self, the symbolic and synchronicity: Virtual realities and the emergence of the $\begin{array}{lllll}\text { psyche. Journal of } & \text { Analytical 271-284. }\end{array}$ https://doi.org/10.1111/j.0021-8774.2005.00531.x

Hogenson, G. B. (2014). Are synchronicities really dragon kings? In H. Atmanspacher, \& C. A. Fuchs (Eds.), The Jung-Pauli Conjecture and its Impact Today (pp. 201-215). Exeter, UK: Imprint Academic.

Hood, R. W., \& Zhuo, C. (2013). Mystical, spiritual, and religious experiences. In R. F. Paloutzian, \& C. L. Parks (Eds.), Handbook of religion and spirituality (2nd ed., pp. 422-440). New York, NY: Guilford Press.

Huntley, H. E. (1970). The divine proportion. New York, NY: Dover Publications.

Iosa, M., Fusco, A., Marchetti, F., Morone, G., Caltagirone, C., Paolucci, S., \& Peppe, A. (2013). The golden ratio of gait harmony: Repetitive proportions of repetitive gait phases. BioMed Research International, 2013. https://doi.org/10.1155/2013/918642

James, W. (1902/1985). The varieties of religious experience. Cambridge, MA: Harvard University Press.

Jung, C. G. (1952). Synchronicity: An acausal connecting principle. The Collected Works of CG Jung, 8.

Kail, R. V., \& Cavanaugh, J. C. (2010). Human development. A life span view. Belmont, CA: Wadsworth.

Kelly, E. W., \& Tucker, J. B. (2015). Research methods with spontaneous case studies. In J. Palmer, \& D. Marcusson-Clavertz (Eds.), Parapsychology: A handbook for the 21st century (pp. 63-76). Jefferson, NC: McFarland.

Kelsey, T. W., Li, L. Q., Mitchell, R. T., Whelan, A., Anderson, R. A., \& Wallace, W. H. B. (2014). A validated age-related normative model for male total testosterone shows increasing variance but no decline after age 40 years. PLoS ONE, 9(10), e109346. https://doi.org/10.1371/journal.pone.0109346 
Kvavilashvili, L., Kornbrot, D. E., Mash, V., Cockburn, J., \& Milne, A. (2009). Differential effects of age on prospective and retrospective memory tasks in young, young-old, and old-old adults. Memory, 17(2), 180-196. https://doi.org/10.1080/09658210802194366

Lagarkova, M. A., Eremeev, A. V., Svetlakov, A. V., Rubtsov, N. B., \& Kiselev, S. L. (2010). Human embryonic stem cell lines isolation, cultivation, and characterization. In Vitro Cellular \& Developmental Biology-Animal, 46(3-4), 284-293. https://doi.org/10.1007/s11626-010-9282-6

Landers, R. N., Brusso, R. C., Cavanaugh, K. J., \& Collmus, A. B. (2016). A primer on theory-driven web scraping: Automatic extraction of big data from the Internet for use in psychological research. Psychological Methods, 21(4), 475-492. https://doi.org/10.1037/met0000081

Linage, G., Montoya, F., Sarmiento, A., Showalter, K., \& Parmananda, P. (2006). Fibonacci order in the period-doubling cascade to chaos. Physics Letters, A359, 638-639. https://doi.org/10.1016/j.physleta.2006.07.036

Lindner, J. F., Kohar, V., Kia, B., Hippke, M., Learned, J. G., \& Ditto, W. L. (2015). Strange nonchaotic stars. Physical Review Letters, 114(5), 054101. https://doi.org/10.1103/PhysRevLett.114.054101

Löwdin, P. O. (1966). Quantum genetics and the aperiodic solid: Some aspects on the biological problems of heredity, mutations, aging, and tumors in view of the quantum theory of the DNA molecule. In P. O. Löwdin (Ed.), Advances in Quantum Chemistry (Vol. 2, pp. 213-360). New York, NY: Academic Press. https://doi.org/10.1016/s0065-3276(08)60076-3

Martin, F., Carminati, F., \& Carminati, G. G. (2010). Quantum information, oscillations and the psyche. Physics of Particles and Nuclei, 4l(3), 425-451. https://doi.org/10.1134/S1063779610030032

Okabe, T. (2011). Physical phenomenology of phyllotaxis. Journal of Theoretical Biology, 280(1), 63-75. https://doi.org/10.1016/j.jtbi.2011.03.037

Paul, S. P. (2016). Golden spirals and scalp whorls: nature's own design for rapid expansion. PloS One, 11(9), e0162026. https://doi.org/10.1371/journal.pone.0162026

Pew Research Center. (2014). Religious landscape survey. Retrieved from http://www.pewforum.org/religious-landscape-study/

Piaget, J. (1970). Piagets theory. In P. H. Mussen (Ed.), Carmichaels Handbook of Child Development (pp. 703-732). New York, NY: Wiley.

Piedmont, R. L. (2005). The role of personality in understanding religious and spiritual constructs. In R. F. Paloutzian, \& C. L. Park (Eds.), Handbook of the psychology of religion and spirituality (pp. 253-273). New York, NY: Guilford Press.

Ricketts, R. M. (1982). Divine proportion in facial esthetics. Clinics in Plastic Surgery, 9(4), 401-422.

Roberts, G. J., Lucas, V. S., Andiappan, M., \& McDonald, F. (2017). Dental age estimation: Pattern recognition of root canal widths of mandibular molars. A novel mandibular maturity marker at the 18 -year threshold. Journal of Forensic Sciences, 62(2), 351-354. https://doi.org/10.1111/1556-4029.13287

Rodgers, C. T., \& Hore, P. J. (2009). Chemical magnetoreception in birds: The radical pair mechanism. Proceedings of the National Academy of Sciences, 106(2), 353-360. https://doi.org/10.1073/pnas.0711968106

Rose, N. (1991). Design and development of wholeness: Waskom's paradigm. The Educational Forum, 55, 243-259. https://doi.org/10.1080/00131729109335650

Russell, P. A. (2000). The aesthetics of rectangle proportion: Effects of judgment scale and context. The American Journal of Psychology, 113(1), 27. https://doi.org/10.2307/1423459

Sacco, R. G. (2013). Re-envisaging the eight developmental stages of Erik Erikson: The Fibonacci Life-Chart Method (FLCM). Journal of Educational and Developmental Psychology, 3(1), 140-146. https://doi.org/10.5539/jedp.v3n1p140

Sacco, R. G. (2016). The Fibonacci Life-Chart Method (FLCM) as a foundation for Carl Jung's theory of synchronicity. Journal of Analytical Psychology, 61(2), 203-222. https://doi.org/10.1111/1468-5922.12204

Sarovar, M., Ishizaki, A., Fleming, G., \& Whaley, K. (2010). Quantum entanglement in photosynthetic light-harvesting complexes. Nature Physics, 6(6), 462-467. https://doi.org/10.1038/nphys 1652 
Smith, T. W. (2006). The national spiritual transformation study. Journal for the Scientific Study of Religion, 45(2), 283-296. https://doi.org/10.1111/j.1468-5906.2006.00306.x

Staff, L., Hurd, P., Reale, L., Seoighe, C., Rockwood, A., \& Gehring, C. (2012). The hidden geometries of the Arabidopsis thaliana epidermis. PloS One, 7(9), e43546. https://doi.org/10.1371/journal.pone.0043546

Stapp, H. (2009). Nonlocality. In D. Greenberger, K. Hentschel, \& F. Weinert (Eds.), Compendium of Quantum Mechanics (pp. 405-410). New York, NY: Springer. https://doi.org/10.1007/978-3-540-70626-7_125

Tehrani, F. R., Solaymani-Dodaran, M., Tohidi, M., Gohari, M. R., \& Azizi, F. (2013). Modeling age at menopause using serum concentration of anti-mullerian hormone. The Journal of Clinical Endocrinology \& Metabolism, 98(2), 729-735. https://doi.org/10.1210/jc.2012-3176

Terracciano, A., Costa, P. T., \& McCrae, R. R. (2006). Personality plasticity after age 30. Personality and Social Psychology Bulletin, 32(8), 999-1009. https://doi.org/10.1177/0146167206288599

Thelen, E., \& Smith, L. B. (1994). A dynamic systems approach to the development of perception and action. Cambridge, MA: MIT Press.

Turin, L. (2002). A method for the calculation of odor character from molecular structure. Journal of Theoretical Biology, 216(3), 367-385. https://doi.org/10.1006/jtbi.2001.2504

Underwood, L. G., \& Teresi, J. A. (2002). The Daily Spiritual Experience Scale: Development, theoretical description, reliability, exploratory factor analysis, and preliminary construct validity using health-related data. Annals of Behavioral Medicine, 24, 22-33. https://doi.org/10.1207/S15324796ABM2401_04

Waskom, J. (1972). The magic of design and other unpublished talks. Loveland, Colorado.

Werdel, M. B., Dy-Liacco, G. S., Ciarrocchi, J. W., Wicks, R. J., \& Breslford, G. M. (2014). The unique role of spirituality in the process of growth following stress and trauma. Pastoral Psychology, 63(1), 57-71. https://doi.org/10.1007/s11089-013-0538-4

Yamagishi, M. E. B., \& Shimabukuro, A. I. (2008). Nucleotide frequencies in human genome and Fibonacci numbers. Bulletin of Mathematical Biology, 70(3), 643-653. https://doi.org/10.1007/s11538-007-9261-6

Zinnbauer, B. J., \& Pargament, K. I. (2005). Religiousness and spirituality. In R. F. Paloutzian, \& C. L. Park (Eds.), Handbook of the psychology of religion and spirituality (pp. 21-42). New York, NY: Guilford Press.

\section{Copyrights}

Copyright for this article is retained by the author(s), with first publication rights granted to the journal.

This is an open-access article distributed under the terms and conditions of the Creative Commons Attribution license (http://creativecommons.org/licenses/by/4.0/). 